\title{
La evaluación de programas educativos como estrategia para la mejora continua
}

Dedicado al lícenciado Héctor de León.

Gracias por el amor, orientación y consejos que me brindaste en todo momento

María Teresa de León Gallo

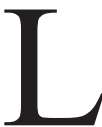

a educación superior en México ha sufrido varios cambios, entre los cuales se encuentran la implementación de diversas políticas y reformas educativas, así como una expansión de instituciones de educación superior (IES), por lo que se exige una rendición de cuentas de sus actividades, lo cual ha generado un interés por ofrecer programas educativos reconocidos debido a la alta calidad académica.

Entre los principales intereses $y$ retos que enfrenta la educación superior está ofrecer una calidad académica en sus programas educativos.

De acuerdo con Gago, H. A. (2012: 59), la calidad de la educación es el:

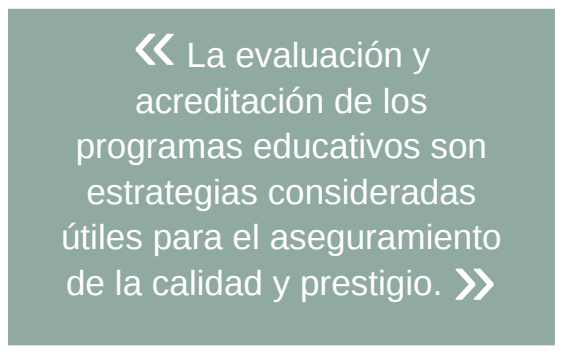

La evaluación y acreditación de los programas educativos son estrategias consideradas útiles para el aseguramiento de la calidad y prestigio, así como para la obtención de recursos financieros, y fungen como parte importante en la toma de decisiones, lo cual es un elemento clave en la planeación institucional. Estos procesos se han convertido en una de las principales prioridades de las IES, ya que de ellos se espera un mejoramiento de planes y programas de estudio, de los procesos de enseñanza y aprendizaje, del personal académico, de estudiantes y de la infraestructura; es decir, que sus resultados conduzcan a buscar soluciones para la mejora continua.

La calidad educativa forma parte de una mejora continua, es considerada como un elemento para la excelencia y la transformación, a través de la cual se puede cumplir con los objetivos, además implica una coherencia entre los fines y las actividades institucionales.

De acuerdo con Martínez Rizo (citado por Zorrilla, 2003: 60 y 61), existen diferentes dimensiones de la calidad educativa, entre las cuales se encuentran: 
Pertinencia y relevancia: cuando se establece un currículo adecuado a las circunstancias de la vida de los alumnos y a las necesidades de la sociedad.

Eficacia interna y exterma: logra que la más alta proporción posible de destinatarios acceda a la escuela, permanezca en ella hasta el final del trayecto, y egrese alcanzando los objetivos de aprendizaje establecidos en los tiempos previstos para ello.

Impacto: consigue que los conocimientos sean asimilados en forma duradera y se traduzcan en comportamientos sustentados en valores individuales y sociales, con lo que la educación será fructífera para la sociedad y el propio individuo, en los diversos papeles que debe jugar.

Eficiencia: cuenta con recursos humanos y materiales suficientes, y los aprovecha de la mejor manera posible, evitando derroches y gastos innecesarios.

Equidad: toma en cuenta la desigual situación de alumnos y familias, de las escuelas mismas, $\mathrm{y}$ ofrece apoyos especiales a quienes lo requieren.

Por lo tanto, la calidad de un programa educativo se establece en la medida en que sea eficaz, eficiente, pertinente, trascendente y equitativo; y la evaluación es un medio que comprueba la eficacia y posibilita el perfeccionamiento de la acción educativa.

Para el aseguramiento de la calidad de los programas educativos, la evaluación y la acreditación son procesos que conducen a la mejora y al cambio institucional, los cuales forman parte de la evaluación educativa, siendo ésta un proceso sistemático, dinámico y continuo, destinado a diagnosticar, controlar, interpretar, orientar y reorientar el proceso educativo, mediante el cual se valora el logro de los objetivos y es útil para determinar la calidad del objeto evaluado, así como para identificar las necesidades existentes para una eficiente toma de decisiones y proponer alternativas de mejora.

La evaluación es considerada como una herramienta útil para el perfeccionamiento y el crecimiento continuo, por lo que es necesario que ésta se realice de manera constante, pertinente y propositiva, que facilite la identificación de fortalezas y áreas de oportunidad, para tomar decisiones y plantear acciones que favorezcan el desarrollo del objeto evaluado.

Dentro de un proceso de evaluación, es importante presentar las fortalezas existentes, con la finalidad de continuar realizando las acciones que llevaron a éstas, así como identificar las áreas de oportunidad para establecer un plan de acción que permita su fortalecimiento y mejora, por lo que se considera de suma trascendencia realizar una evaluación cualitativa y formativa.

Al realizar una evaluación es importante considerar y llevar a la práctica las diferentes normas -útil, factible, ética y exacta- establecidas por el Joint Committee on Standards for Educational Evaluation y la Evaluation Research Society, las cuales forman parte del éxito de una evaluación, puesto que ésta debe ser factible (emplear procedimientos evaluativos que se puedan utilizar sin problema, acordes al objeto evaluado); ética (asegurar la honradez de los resultados, facilitar la cooperación y participación de los diversos actores involucrados, ratificando su protección y confidencialidad); exacta (describir el objeto en su evolución y contexto, al revelar sus fortalezas y áreas de oportunidad, al estar libre de influencias y al proporcionar conclusiones); útil (brindar información y soluciones para la mejora, lo cual hace que la evaluación pueda tener impacto en el objeto evaluado). De igual manera, es necesario dar a conocer su finalidad, tomar en cuenta las condiciones del objeto evaluado, promover entre los participantes (autoridades educativas, profesores y estudiantes) una actitud positiva, de aceptación y colaboración, así como dar un uso adecuado de los resultados, además de un compromiso con la mejora y el crecimiento continuos.

Actualmente, la evaluación tiene gran importancia dentro de las instituciones educativas, ya que está considerada como un medio para lograr la excelencia académica, por lo que es necesaria para el cambio y la innovación, así como la realización

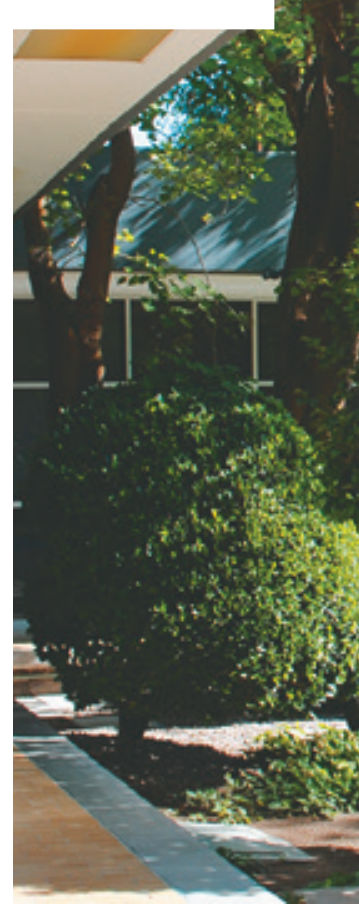


de una autoevaluación, proceso de análisis y reflexión que requieren del trabajo colegiado, con la finalidad de identificar fortalezas y áreas de oportunidad, de diseñar estrategias y acciones que conlleven al logro de la calidad educativa. También es importante que exista un liderazgo, una planeación estratégica, trabajo colaborativo, un compromiso para la mejora continua, un sentido de pertenencia y una corresponsabilidad entre los diferentes actores involucrados, los cuales son elementos clave para el aseguramiento de la calidad de los programas educativos evaluados.

Entre los principales intereses y retos de la Universidad Autónoma de Aguascalientes (UAA) está contar con una excelente calidad académica en sus programas educativos, por lo que se han implementado diferentes procesos, como la evaluación y acreditación de los mismos.
Los programas educativos de las IES son evaluados y acreditados por diferentes organismos especializados, como los Comités Interinstitucionales para la Evaluación de la Educación Superior (CIEES), la Acreditación Nacional, realizada por organismos reconocidos por el Consejo para la Acreditación de la Educación Superior, A.C. (COPAES), así como por la Acreditación Internacional.

Los procesos de evaluación y acreditación de los programas educativos son estrategias para la mejora continua, puesto que son principalmente un motor de cambio que propicia un espacio para la reflexión y autoevaluación; un medio por el cual se identifican las fortalezas y áreas de oportunidad, además de que otorgan propuestas útiles, por lo que han sido considerados, desde hace varias décadas, parte del aseguramiento de la calidad educativa.

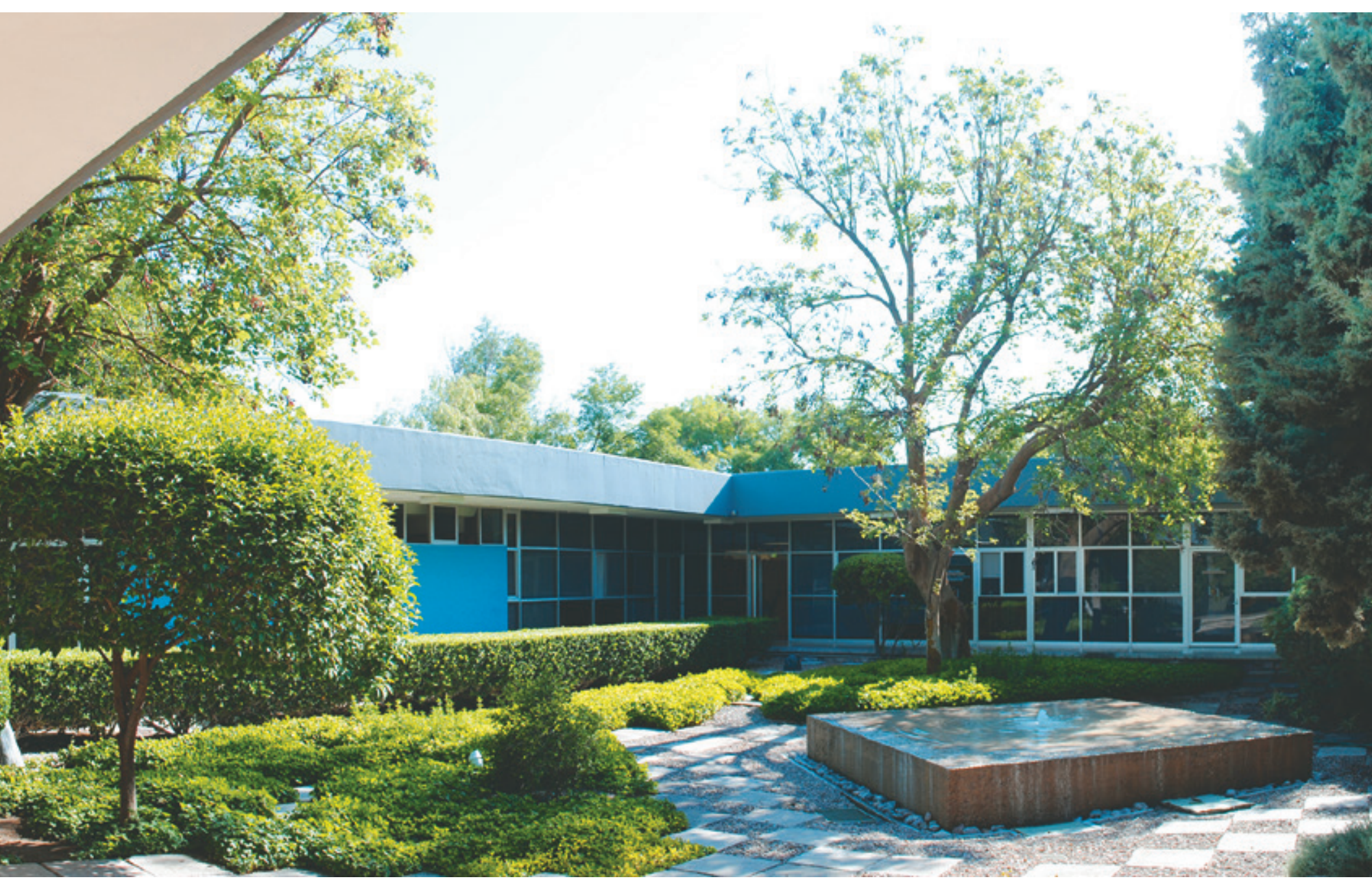


Por lo anterior, las IES están obligadas a la búsqueda de una mejora académica permanente $y$, durante este proceso, el rol de las responsabilidades atañe, sin excepción, a quienes intervienen en las distintas actividades de los programas educativos.

\section{CALIDAD DE LA EDUCACIÓN SUPERIOR}

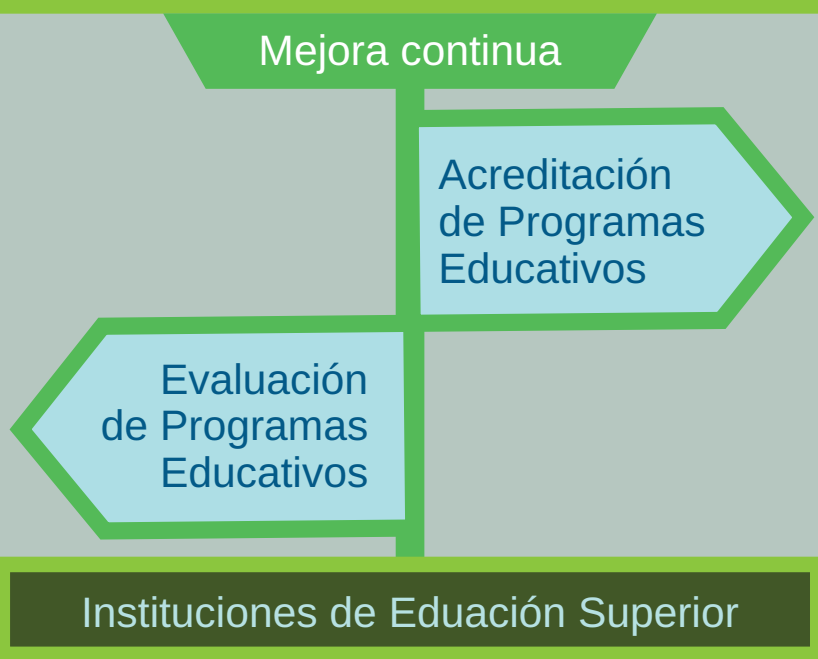

Esquema de estrategias para la mejora continua.

Elaborado por María Teresa de León Gallo.

\section{Fuentes de consulta}

ANUIES. (2004). La evaluación en las Instituciones de Educación Superior. En Evaluación del desempeño del personal académico. México: ANUIES.

Buendía E. A. (2014). Evaluación y acreditación de programas académicos en México: revisar los discursos, valorar los efectos. México: ANUIES.

Escudero E., T. (2003). Desde los tests hasta la investigación evaluativa actual. Un siglo, el XX, de intenso desarrollo de la evaluación en educación. RELIEVE, Vol. 9, Núm. 1, pp. 11-43. Recuperado el 27 noviembre de 2014, en: http:// Www.uv.es/RELIEVE/v9n1/RELIEVEV9n1_1.htm.

Gago, H. A. (2012). Evaluación, certificación y acreditación en la Educación Superior de México. México: ANuIES.

Zorrilla, M. (2003). La evaluación de la educación básica en México 1990-2000. México: UAA. 